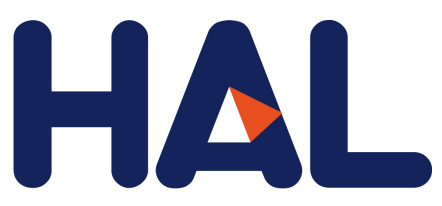

archives-ouvertes

\title{
Injectable silanized hyaluronic acid hydrogel/biphasic calcium phosphate granule composites with improved handling and biodegradability promote bone regeneration in rabbits
}

Killian Flegeau, Olivier Gauthier, Gildas Rethore, Florent Autrusseau, Aurélie Schaefer, Julie Lesoeur, Joëlle Veziers, Anthony Brésin, Hélène Gautier, Pierre Weiss

\section{To cite this version:}

Killian Flegeau, Olivier Gauthier, Gildas Rethore, Florent Autrusseau, Aurélie Schaefer, et al.. Injectable silanized hyaluronic acid hydrogel/biphasic calcium phosphate granule composites with improved handling and biodegradability promote bone regeneration in rabbits. Biomaterials Science, Royal Society of Chemistry (RSC), 2021, 9, pp.5640 - 5651. 10.1039/d1bm00403d . hal-03321748

\section{HAL Id: hal-03321748 \\ https://hal.archives-ouvertes.fr/hal-03321748}

Submitted on 18 Aug 2021

HAL is a multi-disciplinary open access archive for the deposit and dissemination of scientific research documents, whether they are published or not. The documents may come from teaching and research institutions in France or abroad, or from public or private research centers.
L'archive ouverte pluridisciplinaire HAL, est destinée au dépôt et à la diffusion de documents scientifiques de niveau recherche, publiés ou non, émanant des établissements d'enseignement et de recherche français ou étrangers, des laboratoires publics ou privés. 


\title{
(A) Check for updates Injectable silanized hyaluronic acid Cite this: DOI: 10.1039/d1bm00403d hydrogel/biphasic calcium phosphate granule composites with improved handling and biodegradability promote bone regeneration in rabbits $\uparrow$
}

\author{
Killian Flegeau, a,b,c Olivier Gauthier, ${ }^{a, b, d}$ Gildas Rethore, ${ }^{\text {a,b,e }}$ Florent Autrusseau, ${ }^{a, b, f}$ \\ Aurélie Schaefer, ${ }^{a, b, g}$ Julie Lesoeur, a,b,g Joëlle Veziers, ${ }^{a, e, g}$ Anthony Brésin, ${ }^{c}$ \\ Hélène Gautier (ID) a,b,h and Pierre Weiss (D) *a,b,e
}

Biphasic calcium phosphate (BCP) granules are osteoconductive biomaterials used in clinics to favor bone reconstruction. Yet, poor cohesivity, injectability and mechanical properties restrain their use as bone fillers. In this study, we incorporated BCP granules into in situ forming silanized hyaluronic acid (Si-HA) and hydroxypropylmethylcellulose (Si-HPMC) hydrogels. Hydrogel composites were shown to be easily injectable $(F<30 \mathrm{~N})$, with fast hardening properties $(<5 \mathrm{~min})$, and similar mechanical properties $(E \sim 60$ $\mathrm{kPa}$ ). In vivo, both hydrogels were well tolerated by the host, but showed different biodegradability with $\mathrm{Si}-\mathrm{HA}$ gels being partially degraded after 21d, while Si-HPMC gels remained stable. Both composites were easily injected into critical size rabbit defects and remained cohesive. After 4 weeks, Si-HPMC/BCP led to poor bone healing due to a lack of degradation. Conversely, Si-HA/BCP composites were fully degraded and beneficially influenced bone regeneration by increasing the space available for bone ingrowth, and by

Received 16th March 2021 Accepted 9th June 2021

DOI: $10.1039 / \mathrm{d} 1 \mathrm{bm} 00403 \mathrm{~d}$

rsc.li/biomaterials-science accelerating BCP granules turnover. Our study demonstrates that the degradation rate is key to control bone regeneration and that $\mathrm{Si}-\mathrm{HA} / \mathrm{BCP}$ composites are promising biomaterials to regenerate bone defects.

\section{Introduction}

The burden of bone diseases is a major healthcare concern and accounts for half of the chronic diseases in people aged 50 or more. ${ }^{1}$ Despite bone's innate ability to self-repair, adverse events such as injuries, tumor resections or non-union fractures may not heal properly, requiring surgical intervention. ${ }^{2}$ In such cases, autologous bone grafts remain the "gold

\footnotetext{
${ }^{a}$ Université de Nantes, ONIRIS, Inserm UMR 1229, RMeS, Regenerative Medicine and Skeleton, Nantes F-44042, France.E-mail: pierre.weiss@univ-nantes.fr

${ }^{b}$ Université de Nantes, UFR Odontologie, Nantes, F-44042, France

${ }^{c}$ HTL S.A.S, Javené, France

${ }^{d}$ Department of Experimental Surgery, CRIP, Oniris, Nantes, F-44300, France ${ }^{e} \mathrm{CHU}$ Nantes, PHU4 OTONN, Nantes F-44093, France

${ }^{f_{E}}$ cole Polytechnique de l'Université de Nantes, rue Ch. Pauc, Nantes, F-44300, France

${ }^{g}$ SC3M, SFR Santé F. Bonamy, FED 4203, UMS Inserm 016, CNRS 3556, Nantes F-44042, France

${ }^{h}$ Université de Nantes, Faculté de Pharmacie, Laboratoire de Pharmacie Galénique, Nantes F-44042, France

$\dagger$ Electronic supplementary information (ESI) available. See DOI: 10.1039/ d1bm00403d
}

standard", although being associated with limited availability, risk of contamination, and need for two surgeries. ${ }^{3}$ In this context, biomaterials have emerged as a potent alternative to treat bony defects. ${ }^{4,5}$ Notably, biphasic calcium phosphates (BCP), made of hydroxyapatite and $\beta$-tricalcium phosphate, are particularly interesting due to their controlled resorption rate, ${ }^{6,7}$ and osteoconductive properties. ${ }^{8}$ Their granular formulation facilitates cellular infiltration, protein adsorption and cell attachment. ${ }^{9}$ In addition, BCP granules show osteogenic properties, able to stimulate the differentiation of stem cells through the progressive release of calcium and phosphate ions. ${ }^{10,11}$ However, granules require open surgeries and are inherently limited by their poor cohesivity, injectability and mechanical properties, impeding their use as bone fillers. ${ }^{9}$ Injectable biomaterials were developed by combining BCP granules with natural (e.g., fibrin, ${ }^{12}$ hyaluronic acid ${ }^{13}$ ) or hemisynthetic (e.g., cellulose derivatives $\left.{ }^{14}\right)$ polymers to form putties and pastes; ${ }^{15}$ yet with poor outcomes regarding short-term implant stability and granules wash-out by body fluids. ${ }^{14,16}$

In situ forming hydrogels that can be injected into a tissue in a minimally invasive fashion are a promising solution to improve handling, injectability, and stability of the biomater- 
ial. ${ }^{17}$ Hydrogels are water-swollen, three-dimensional chemically crosslinked scaffolds, ${ }^{18}$ with high biocompatibility and ability to incorporate cells, drugs, and small particles. ${ }^{19,20}$ Besides, hydrogels reduce phase separation and increase mechanical stability when mixed with calcium phosphate granules. ${ }^{17}$ Unfortunately, very few chemistries are compatible with simultaneous granules loading, in situ formation and defect filling. Photopolymerization is limited by the finite penetration of light in tissues, Schiff-base, Michael addition and ionotropic bonds are very unstable in vivo, and enzymatic crosslinking have ultrafast gelation properties that restrain their injectability properties. ${ }^{21}$ Our laboratory previously developed silanized hydroxypropylmethylcellulose (Si-HPMC) hydrogels crosslinked through the inorganic polymerization of silicon alkoxides into siloxane bonds. ${ }^{22}$ These hydrogels showed optimal injectability and gelation time, suitable for BCP granules incorporation and injection in vivo. ${ }^{23}$ However, long-term implantations revealed large non-regenerated areas into rabbit critical-size defects, ${ }^{23}$ supposedly due to the lack of degradability of cellulosic derivatives. Thus far, no hydrogels have succeeded in combining good handling properties, mechanical stability and controlled in vivo degradation. We recently reported the development of silanized in situ forming hyaluronic acid hydrogels (Si-HA) with tunable mechanical properties and degradation times in vivo that show good biocompatibility and tissue integration. ${ }^{24}$ Hyaluronic acid is an ubiquitous glycosaminoglycan widely employed for its intrinsic biocompatibility and biodegradability through hyaluronidases activity. ${ }^{25}$ In addition, HA is known to have osteogenic properties due to its proangiogenic behavior and ability to interact with cells and cytokines (e.g., BMP-2). ${ }^{26}$ The aim of this article was to evaluate the ability of Si-HA gels loaded with BCP granules to facilitate bone regeneration in critical-size bone defects, in comparison with Si-HPMC/BCP composites. We first designed Si-HPMC and Si-HA hydrogels and compared their physicochemical properties as well as their biocompatibility and biodegradability in vivo. Si-HPMC/BCP and Si-HA/ BCP composites were further developed and their ability to regenerate bone defects was evaluated after 4 weeks of implantation into the distal end of rabbit femurs by micro-computed tomography, scanning electron microscopy (SEM) and histology. This study offers meaningful insights for the development of biodegradable, biocompatible hydrogel/calcium phosphate composites for the treatment of bone loss.

\section{Material and methods}

\subsection{Materials}

Hyaluronic acid sodium salt (420 kDa) was provided by HTL S. A.S (France). Hydroxypropylmethylcellulose (HPMC) was provided by Colorcon-Dow Chemical (USA). 2-( $N$-Morpholino)ethanesulfonic acid (MES) and 4-(4,6-dimethoxy-1,3,5-triazin-2-yl)4-methyl-morpholinium chloride (DMTMM) were purchased from TCI Europe (Belgium). 1-Propanol and 100\% ethanol were bought from VWR (USA). BCP granules (MBCP ${ }^{\mathrm{TM}}$;
$40-80 \mu \mathrm{m})$ with a $60 / 40$ hydroxyapatite/ $\beta$-tricalcium phosphate weight ratio were purchased from Biomatlante (France) (Fig. A1 $\dagger$ ). Penicillin/streptomycin and phosphate buffered saline (PBS) were purchased from ThermoFisher Scientific (USA). Human bone marrow mesenchymal stem cells (hBMSCs), Mesenchymal Stem Cells growth media2 and Supplement Mix were bought from Promocell (Germany). Ketamine (Imalgène ${ }^{\circledR 1000)}$ ) and Xylazine (Rompun $\left.{ }^{\circledR}\right)$ were respectively purchased from Merial (France) and Bayer Medical (Germany). Otherwise stated, all other reagents were purchased from Sigma Aldrich (Switzerland).

\subsection{Silanization of HPMC and HA}

Si-HPMC and Si-HA conjugates were prepared following previously described procedures. ${ }^{22,24}$ Briefly, Si-HPMC conjugates were synthetized by adding 1.5 eq. of (3-glycidyloxypropyl)trimethoxysilane (GPTMS) into a mixture of HPMC powder, 1-propanol, $n$-heptane and sodium hydroxide $(\mathrm{NaOH})$ under nitrogen bubbling at $85{ }^{\circ} \mathrm{C}$ for 3.5 hours. Si-HA was obtained by amidation of the carboxylic groups using 2 eq. of DMT-MM for $1 \mathrm{~h}$ and 2 eq. of (3-aminopropyl)triethoxysilane (APTES) for $24 \mathrm{~h}$ at $23^{\circ} \mathrm{C}$. Si-HPMC and Si-HA were purified and silanol grafting was followed by ${ }^{1} \mathrm{H}-\mathrm{NMR}$ (ESI $\dagger$ ).

\subsection{Formulation of Si-HPMC and Si-HA hydrogels}

Si-HPMC and Si-HA conjugates were respectively dissolved in $\mathrm{NaOH} 0.1 \mathrm{~N}$ at a $3 \%(\mathrm{w} / \mathrm{v})$ and $3.75 \%(\mathrm{w} / \mathrm{v})$ polymer concentration. Si-HPMC solutions were steam sterilized by autoclaving and Si-HA solutions were sterile-filtered using $0.22 \mu \mathrm{m}$ filters. Using Luer-lock syringes, the solutions were mixed with 4-(2-hydroxyethyl)-1-piperazineethanesulfonic acid (HEPES) buffers to obtain final polymer concentrations of $3 \%(\mathrm{w} / \mathrm{v})$ for Si-HA and $2 \%(\mathrm{w} / \mathrm{v})$ for Si-HPMC. These values were determined as the minimum concentration required to form stable hydrogels and were kept constant throughout the study. HEPES buffers were adapted to obtain a final $\mathrm{pH}$ of 7.4 and an osmolarity of 300 mOsm (ESI $\dagger$ ).

\subsection{Formulation of Si-HPMC/BCP and Si-HA/BCP composites}

Prior to composite preparation, BCP granules were decontaminated by a dry-heat treatment $\left(180{ }^{\circ} \mathrm{C}, 1 \mathrm{~h}\right)$ and poured into $3 \mathrm{~mL}$ Luer-lock syringes. Si-HPMC and Si-HA were prepared as described above using Luer-lock syringes. After mixing the two solutions, BCP granules and hydrogel precursor solutions were added in a 50/50 weight ratio and mixed again to homogenize the suspension before injection.

\subsection{Viscosity profiles and zero-shear viscosity}

Viscosity measurements of Si-HPMC and Si-HA solutions were performed on a stress-controlled RS300 rheometer (HAAKE, ThermoFisher Scientific, USA) with a cone/plate $60 \mathrm{~mm} 1^{\circ}$ titanium geometry in a shear rate range of 0.1 to $2000 \mathrm{~s}^{-1}$. 


\subsection{Injectability}

Injectability of Si-HPMC and Si-HA solutions \pm BCP granules through a 18 Gauge needle was performed on a texture analyzer (TAHD+, Stable Micro Systems, United Kingdom) equipped with a $5 \mathrm{~kg}$ load cell at a rate of $2 \mathrm{~mm} \mathrm{~s}^{-1}$ and recorded on the Exponent software.

\subsection{Gelation profiles}

The gelation profiles of Si-HPMC and Si-HA solutions \pm BCP granules were studied by performing a time sweep $(1 \mathrm{~Hz}, 1 \mathrm{~Pa})$ on a RS300 rheometer, using a plate/plate $60 \mathrm{~mm} 1^{\circ}$ titanium geometry.

\subsection{In vitro enzymatic degradation}

In vitro enzymatic degradation of Si-HPMC and Si-HA hydrogels \pm BCP granules was monitored over 4 days. Hydrogel samples were weighted $\left(w_{\mathrm{a}}\right)$ and soaked into $10 \mathrm{U} \mathrm{mL}^{-1}$ hyaluronidase at $37{ }^{\circ} \mathrm{C}$. Samples were regularly gently dried by removing excess water and weighted $\left(w_{\mathrm{b}}\right)$. The degradation kinetics was followed by calculating the percentage of the remaining hydrogel mass $\left(w_{\mathrm{b}} / w_{\mathrm{a}} \times 100\right)$. Fresh hyaluronidase solution was replaced every time.

\subsection{Unconfined compression}

Unconfined compression tests of Si-HPMC and Si-HA hydrogels \pm BCP granules were performed on cylindrical samples $(6 \mathrm{~mm} \times 10 \mathrm{~mm})$ on a Texture Analyzer and recorded on the Exponent Software. Hydrogels were left for crosslinking for 3 days at $37{ }^{\circ} \mathrm{C}$ before analysis at a constant compression rate of $0.01 \mathrm{~mm} \mathrm{~s}^{-1}$. The elastic modulus $(E)$ was determined as the slope of the first $10 \%$ of the stress versus strain curve.

\subsection{Cell culture}

hBMSCs were cultured in complete Promocell's Growth Media 2 supplemented with $1 \%$ penicillin/streptomycin. To evaluate samples cytocompatibility, hBMSC were platted on a 96-well plate for $24 \mathrm{~h}$ before adding the samples. After 1, 3 and 7 days, samples were removed and the metabolic activity of hBMSC was assessed using a Cell Counting Kit-8 (CCK8) and a plate reader (Victor 3V, PerkinElmer, USA) at $450 \mathrm{~nm}$. Actinomycin$\mathrm{D}\left(5 \mu \mathrm{g} \mathrm{mL} \mathrm{m}^{-1}\right)$ was used as a negative control of metabolic activity.

\subsection{In vivo implantation}

All procedures involving the use of animals were in accordance with the European Community Guidelines for the care and use of laboratory animals (2010/63/UE) and approved by the national ethical committee (Apafis 10595 and Apafis 12838) and the Oniris Animal Welfare committee. Surgical procedures were performed according to the Good Laboratory Practices at the Oniris College of Veterinary Medicine of Nantes. Subcutaneous injections of Si-HPMC and Si-HA gels were performed on 4 female C57BL/6 mice (12 weeks), purchased from Charles River (USA). General anesthesia was performed by a single injection of ketamine/xylazine. $250 \mu \mathrm{L}$ of sterile $2 \% \mathrm{w} / \mathrm{v}$
Si-HPMC and 3\% w/v Si-HA hydrogels were prepared under aseptic conditions and subcutaneously injected in the back of each mouse ( $n=6$ per condition). After $21 \mathrm{~d}$, mice were euthanized by $\mathrm{CO}_{2}$ inhalation, and hydrogels were collected, fixed, and embedded in paraffin wax.

In vivo rabbit implantation were performed as previously described. ${ }^{23}$ Nine adult female New Zealand white rabbits, aged 16 weeks old and weighted 3 to $3.5 \mathrm{~kg}$, were purchased from Charles River Laboratories (France). General anesthesia was carried out by intramuscular injection of ketamine/xylazine. After clipping and skin disinfection with iodine solution, a lateral arthrotomy of the knee joint was performed. Cylindrical defects ( $6 \mathrm{~mm}$ diameter $\times 10 \mathrm{~mm}$ height $)$ were performed at the junction between the epiphysis and the metaphysis using motor-driven drill bits with successive 2-, 4- and $6 \mathrm{~mm}$ diameter. Bone defects were rinsed by saline injection. In parallel, composites were prepared extemporaneously under aseptic conditions and injected into the femoral cavity using $18 \mathrm{G}$ needles. 2 holes were left empty, 3 defects were filled with Si-HA hydrogel, 3 with BCP granules alone and 5 defects were filled with Si-HPMC/BCP or Si-HA/BCP composites $(n=5$ per condition). No condition with Si-HPMC hydrogels alone was used to refine animal number. BCP granules were deposited with a sterile spatula and mixed with blood to improve cohesivity and bioactivity. Subcutaneous tissues and skin were closed in different layers with surgical sutures and a final bandage was added. The surgical procedure was performed bilaterally. After 4 weeks, rabbits were anaesthetized and euthanized by intracardiac overdose of sodium pentobarbital. The femoral condyles were harvested and directly soaked into PFA 4\% for 48 hours.

\subsection{Microcomputed tomography $(\mu \mathrm{CT})$}

Microcomputed tomography $(\mu \mathrm{CT})$ analyses were performed on a Skyscan 1272 X-ray Micro-CT (Bruker, USA). Acquisitions were performed at a spatial resolution of $20 \mu \mathrm{m}$ with a rotation step of $0.5^{\circ}$. A $0.11 \mathrm{~mm}$-thick copper filter was used (voltage: $100 \mathrm{kV}$; current: $100 \mu \mathrm{A}$ ). Three-dimensional reconstructions were performed using the NRecon software, post-treated with the CTan software and imaged with the Dataviewer software. The same grayscale threshold was applied to distinguish bone, BCP granules and connective tissues.

\subsection{Scanning electron microscopy (SEM)}

Following $\mu \mathrm{CT}$ analyses, samples were embedded in glycol methyl methacrylate (GMA) resin without decalcification. Each sample was cut in half with a diamond saw (saw microtome 1600 , Leica). The surface of the implant was polished on a MetaServ $^{\mathrm{TM}} 250$ polisher (Buehler, USA) and sputtered with gold/palladium alloy (Desk V, Denton Vacuum, USA). SEM analyses were performed on a LEO1450VP (Zeiss, Germany) using backscattered electrons (BSE) at $15 \mathrm{kV}$.

\subsection{Histology}

The other half was cut into $7 \mu$ m-thick sections using a hard tissue microtome (Reichert-Jung, Supercut 2050, Germany). 
Movat and Goldner's pentachrome staining were performed on three different implant levels. HES and anti-CD68 staining (ESI $\dagger$ ) were performed on $5 \mu \mathrm{m}$ thick sections of subcutaneous implants. Stained sections were recorded on a whole slide imager (Nanozoomer HamaMatsu, Japan) and visualized with the NDP.view2 software. Quantitative evaluation of the fibrous capsule and peri-implant cell density were performed using the ImageJ software ( $n=9$ images per condition). Bone formation were characterized by software analyses (ESI $\dagger$ ). Osteoclastic activity was detected by staining histological sections with tartrate-resistant acid phosphate (TRAP) using a previously published protocol ${ }^{27}$ with $45 \mathrm{~min}$ incubation at $37^{\circ} \mathrm{C}$.

\subsection{Statistical analyses}

All quantitative results are presented a mean \pm standard deviation (SD). Physicochemical characterization of hydrogels \pm BCP granules were performed on 9 samples and compared using Student unpaired $t$-tests. Evaluation of cytocompatibility was performed with 3 independent experiments and compared using a two-way Anova. Evaluation of bone regeneration by $\mu \mathrm{CT}$ and SEM, as well as BCP surface and osteoid barrier areas were compared using one-way Anova tests. For all experiments, a statistical significance level of $\alpha=0.05$ was chosen.

\section{Results}

\subsection{Synthesis, formulation, and characterization of Si-HA and Si-HPMC hydrogels}

To evaluate the potential of silanized polymers as injectable bone substitutes, Si-HPMC and Si-HA hydrogels were first developed and characterized. Si-HPMC was synthetized by grafting GPTMS to the cellulosic ether (Fig. 1A \& B), ${ }^{22}$ and HA was silanized by grafting APTES to the carboxylic ends of the backbone (Fig. 1C \& D). Both hydrogels formed following polymer dissolution in $\mathrm{NaOH} 0.1 \mathrm{~N}$ and subsequent mixing with an acidic HEPES buffer, triggering the polycondensation of silanols into covalent siloxane bonds (Fig. 1E). To serve as in situ forming carriers, hydrogels were optimized to be easily injected, with rapid gelation upon injection, and stability overtime. Upon dissolution, both polymers showed low viscosity profiles (Fig. 1F), although Si-HPMC solutions were more viscous than Si-HA. They were easily injected through $18 \mathrm{G}$ needles, with extrusion forces of $5.8 \pm 2.3 \mathrm{~N}$ and $3.8 \pm 0.3 \mathrm{~N}$ for Si-HPMC and Si-HA, respectively (Fig. 1G). After injection, SiHPMC and Si-HA solutions gelled in less than $5 \mathrm{~min}$ and reached similar mechanical properties $(E>2 \mathrm{kPa})$ after complete crosslinking (Fig. A2 $\dagger$ ). In contact with hyaluronidase, SiHPMC gels remained stable overtime, demonstrating no signs of swelling or degradation. Conversely, Si-HA gels swelled during the first $24 \mathrm{~h}$, before being progressively degraded within 4 days (Fig. $1 \mathrm{H}$ ). To evaluate hydrogels biocompatibility and degradation in vivo, subcutaneous injections were performed on immunocompetent C57BL/6 mice. After $21 \mathrm{~d}$, gels were explanted and analyzed by HES and anti-CD68 staining. Both gels elicited a local inflammatory response, characterized by a fibrous capsule surrounding the implants and the presence of inflammatory cells within this capsule. The fibrous capsule was very similar for both hydrogels, with a comparable thickness of $92.6 \pm 32.4 \mu \mathrm{m}$ and $120.4 \pm 32.2 \mu \mathrm{m}$ for Si-HPMC and Si-HA, respectively (Fig. 1I). However, a higher cell density in the peri-implant tissue was observed in Si-HPMC samples $\left(289.7 \pm 80.9\right.$ cells per $\left.\mathrm{Mpixel}^{2}\right)$ compared to Si-HA samples (196.4 \pm 48.2 cells per Mpixel ${ }^{2}$ ) (Fig. 1J). Interestingly, while $\mathrm{CD} 8^{+}$macrophages, and some multinucleated giant cells, mainly lined against the Si-HPMC gels without any sign of degradation or infiltration, they were able to infiltrate and degrade Si-HA gels, with additional signs of new matrix secretion by fibroblasts (Fig. 1K). Although not fully resorbed after $21 \mathrm{~d}$, Si-HA gels were shown to be more biodegradable than Si-HPMC samples and to induce a less pronounced inflammatory response in a subcutaneous site.

\subsection{Formulation and characterization of composite hydrogels}

We next developed hybrid hydrogel/calcium phosphate composites by mixing BCP granules with Si-HPMC or Si-HA solutions. The addition of granules led to the formation of viscous pastes that hardened and formed stable composites within $5 \mathrm{~min}$ (Fig. 2A). Addition of BCP granules significantly increased the extrusion force required to inject the composites, with values of $13.9 \pm 2.0 \mathrm{~N}$ and $24.0 \pm 6.0 \mathrm{~N}$, for Si-HPMC/BCP and Si-HA/ BCP composites, respectively (Fig. 2B). Besides, adding BCP granules did not modify the crosslinking profiles of Si-HA and Si-HPMC gels, enabling the formation of rapidly setting bone substitutes (Fig. 2C). In addition, the mechanical properties after complete crosslinking were increased, with elastic moduli of $59.8 \pm 30.5$ and $67.6 \pm 27.4 \mathrm{kPa}$ for Si-HPMC/BCP and Si-HA/ BCP composites, respectively (Fig. 2D). Like their BCP-free counterparts, Si-HPMC/BCP remained stable over the 4-day period when soaked in $10 \mathrm{U} \mathrm{ml}^{-1}$ hyaluronidase solution. In contrast, Si-HA/BCP gels were rapidly degraded in less than $2 \mathrm{~d}$ (Fig. 2E). The cytocompatibility of the Si-HPMC/BCP and SiHA/BCP composites was evaluated by measuring the metabolic activity of hBMSCs in contact with the biomaterials (Fig. 2F). No statistical differences in the metabolic activity were noticed between the positive control and the biomaterials over the 7-day period, indicating that neither the hydrogels nor the BCP granules negatively impacted hBMSCs metabolic activity.

\subsection{Microcomputed tomography and SEM analysis}

The ability of Si-HPMC/BCP and Si-HA/BCP composites to be used as injectable bone substitutes and favor bone regeneration was evaluated by injecting the biomaterials for 4 weeks into critical-size defects performed at the distal end of rabbit femurs. All composite hydrogels were prepared extemporaneously and easily injected in a one-step procedure and led to complete defect filling. Conversely, implantation of BCP granules required multiple steps to fulfill the defect, with granules leakage outside the defect. Nevertheless, all animals recovered well from the surgical procedure with no signs of adverse inflammation. Four weeks after the implantation, samples 
A

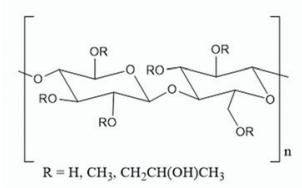

C

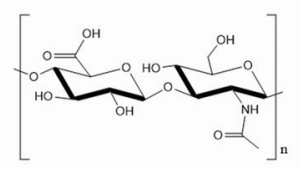

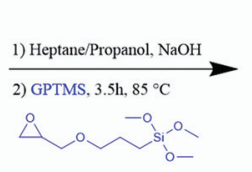

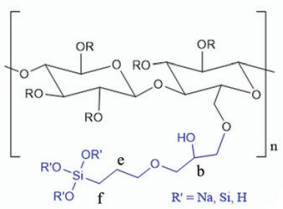

B

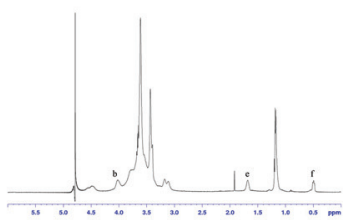

D
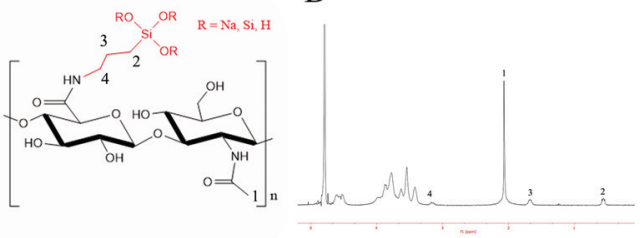
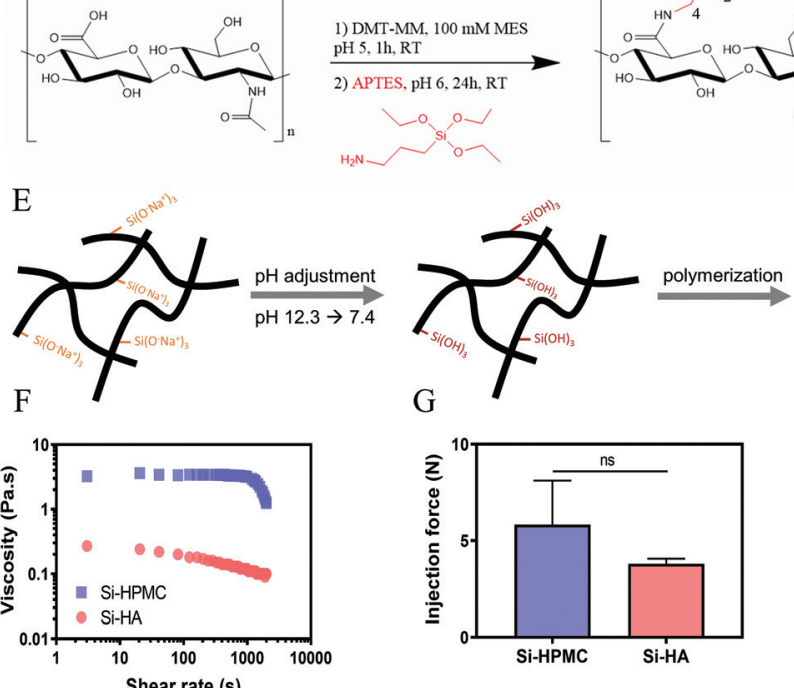

G
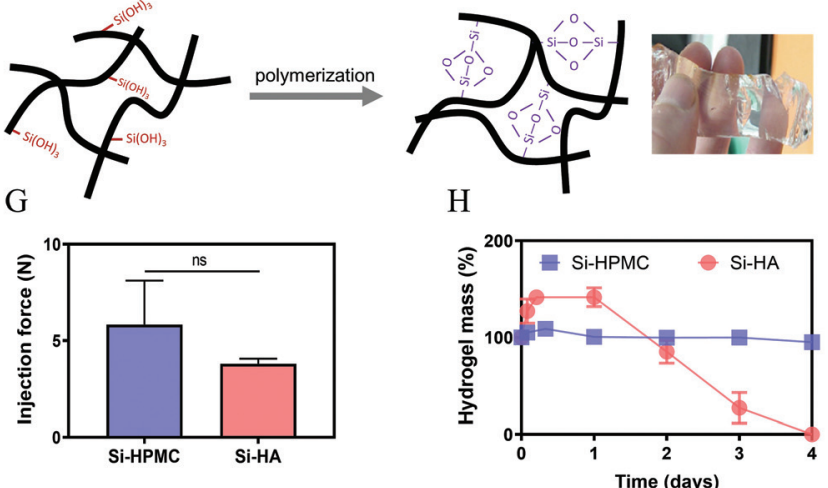

I

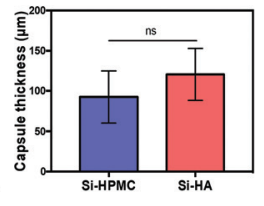

K
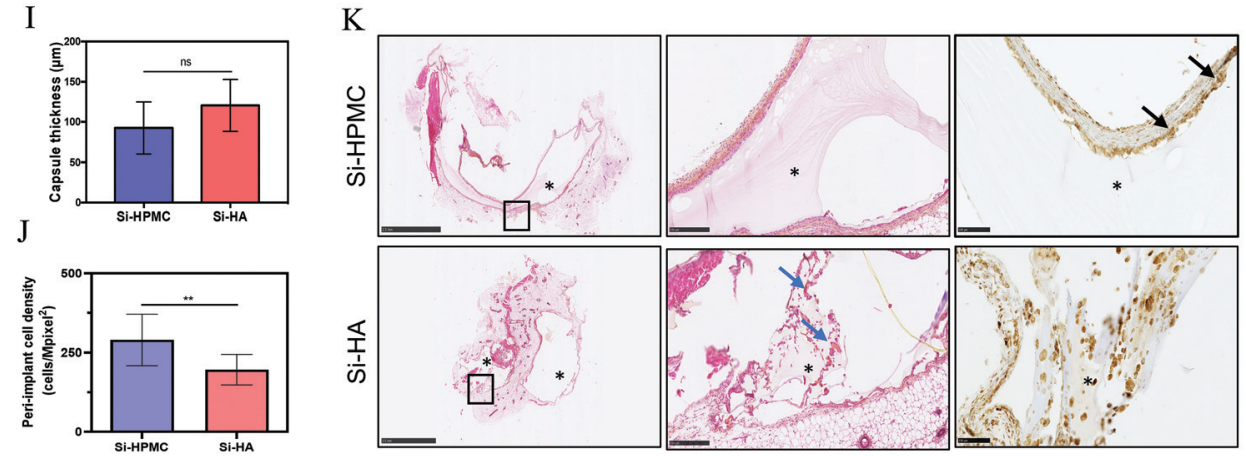

Fig. 1 Development and characterization of $2 \% \mathrm{w} / \mathrm{v}$ Si-HPMC and 3\% w/v Si-HA hydrogels. Synthesis of (A) Si-HPMC and (C) Si-HA, (B) Representative ${ }^{1} \mathrm{H}-\mathrm{NMR}$ spectrum of Si-HPMC in $\mathrm{D}_{2} \mathrm{O} / \mathrm{NaOD}$, adapted from Guillory et al., ${ }^{28}$ and (D) Si-HA in NaOD, (E) general formulation of hydrogels. Silanized polymers are dissolved in $\mathrm{NaOH} 0.1 \mathrm{~N}$ and mixed with a HEPES buffer to form covalent gels at pH 7.4, (F) viscosity profiles of Si$\mathrm{HPMC}$ and $\mathrm{Si}-\mathrm{HA}$ precursor solutions at $23^{\circ} \mathrm{C},(\mathrm{G})$ extrusion forces required to inject Si-HPMC and Si-HA solutions through a $18 \mathrm{G}$ needle, (H) enzymatic degradation of Si-HPMC and Si-HA hydrogels in the presence of hyaluronidase $10 \mathrm{U} \mathrm{mL}^{-1}$ at $37^{\circ} \mathrm{C}$, (I) thickness of the fibrous capsule surrounding implants after $21 \mathrm{~d}$, (J) density of cells in the peri-implant tissue after $21 \mathrm{~d}$, (K) HES staining and CD68 immunostaining of Si-HA and SiHPMC, $21 \mathrm{~d}$ after implantation. Scale bar: $100 \mu \mathrm{m}$. Blue arrows indicate new matrix secretion by fibroblasts. CD68 ${ }^{+}$macrophages are stained in brown. Cell nuclei and hydrogels are stained in blue. Black arrows indicate giant cells. *: Hydrogel. Data are presented as mean \pm SD. Statistical significance was determined by Student $t$-tests (ns: not significant, ${ }^{* *} p<0.01$ ).

were harvested and bone formation was evaluated and quantified by 2 methods, namely $\mu \mathrm{CT}$ (3D) and SEM (2D) (Fig. 3A \& E). The absence of spontaneous healing in empty defects was first confirmed (Fig. A3†). Quantification of bone regeneration by $\mu \mathrm{CT}$ and SEM revealed limited tissue regeneration in Si-HA gels alone, with only $15.3 \pm 1.8 \%$ and $17.3 \pm 9.4 \%$ of newly mineralized tissue after $21 \mathrm{~d}$, respectively (Fig. 3B \& C). This regeneration was only observed at the edge of the defects.
Conversely, defects filled with BCP granules alone were dense, homogeneous, and well regenerated, with $54.1 \pm 1.4 \%$ and $39.5 \pm 3.9 \%$ of newly mineralized tissue obtained by $\mu \mathrm{CT}$ and SEM, respectively. Interestingly, filling defects with Si-HA/BCP composites showed a similar bone tissue regeneration, with $42.9 \pm 6.8 \%$ and $39.7 \pm 5.3 \%$ of newly mineralized tissue, as determined by $\mu \mathrm{CT}$ and SEM, respectively. However, statistically less bone formation was observed for the Si-HPMC/BCP 


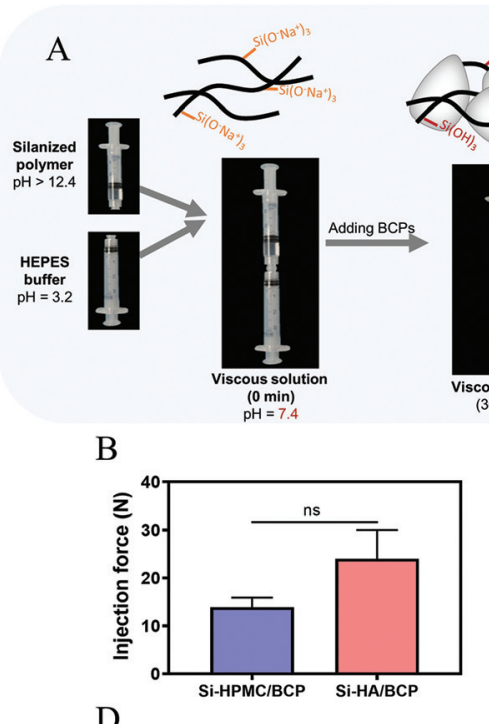

D

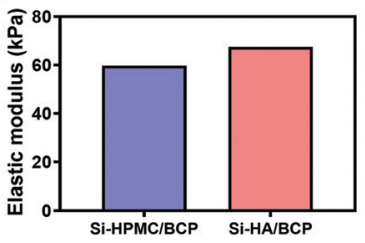

$\mathrm{E}$

$\mathrm{C}$
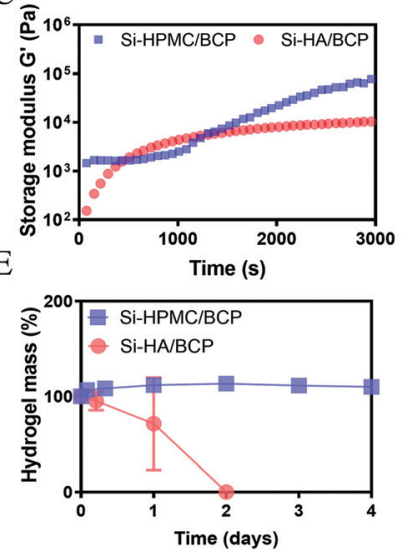

$\mathrm{F}$

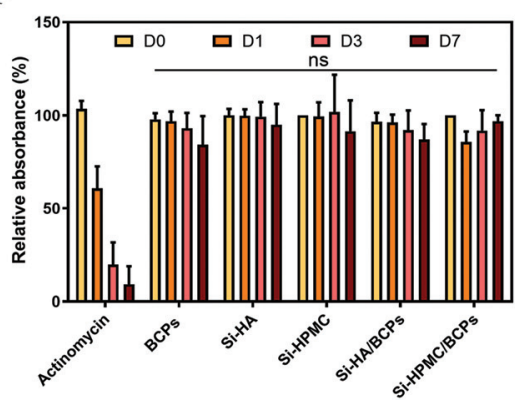

Fig. 2 Development, characterization, and in vitro evaluation of hydrogel/BCP composites. (A) Formulation of hydrogel/BCP composites. BCP granules are added to the pre-mixed polymer solution using Luer-lock syringes. A viscous paste is obtained that hardened within 5 min, (B) injectability of Si-HPMC/BCP and Si-HA/BCP composites through a $18 \mathrm{G}$ needle, (C) crosslinking profiles of Si-HPMC/BCP and Si-HA/BCP composites at $37^{\circ} \mathrm{C}(1$ $\mathrm{Pa} ; 1 \mathrm{~Hz}$ ), (D) elastic moduli of composites after complete crosslinking, (E) enzymatic degradation of Si-HPMC/BCP and Si-HA/BCP composites in the presence of hyaluronidase $10 \mathrm{U} \mathrm{mL}^{-1}$ at $37^{\circ} \mathrm{C},(\mathrm{F})$ metabolic activity of hBMSC in the presence of the polymers, BCP granules or composites, after 1,3 and 7 days, as determined by a CCK8 assay. Data are presented as mean \pm SD. Statistical significance was determined by Student $t$-tests and a two-way Anova (E) (ns: not significant).

composites, with $30.8 \pm 2.7 \%$ and $22.5 \pm 7.2 \%$ of regenerated tissue obtained by $\mu \mathrm{CT}$ and SEM, respectively.

Careful analysis of SEM images revealed areas of osteoconduction around the granules and formation of trabecular-like structures (orange squares) and osteocyte lacunae (Fig. 3E), indicating mature bone formation in BCP-containing samples. Poorly regenerated areas were also observed (red squares), although being predominantly visible in the Si-HPMC/BCP samples. To evaluate BCP granules resorption, the mean area of particles in samples containing BCP granules was further quantified by SEM (Fig. 3D). A statistically smaller mean particle area was observed within Si-HA hydrogels $(164.0 \pm 31.9$ pixel $\left.^{2}\right)$, as compared to BCP granules alone $\left(251.6 \pm 9.1\right.$ pixel $\left.^{2}\right)$ or Si-HPMC/BCP composites $\left(224.9 \pm 25.0\right.$ pixel $\left.^{2}\right)$, suggesting a greater resorption of BCP granules in Si-HA/BCP samples.

\subsection{Histological evaluation of bone formation and remodeling}

Bone regeneration was finally characterized by histological examination of Goldner-stained tissue sections (Fig. 4A). Excellent tissue integration and no signs of fibrous encapsulation were observed in all implants containing BCP granules after 4 weeks (Fig. A4†). Implants filled with Si-HA hydrogels alone showed an irregular fibrous capsule surrounding the implant and limited to no cell infiltration. After 4 weeks, clear differences in biomaterials resorption and bone formation 
A

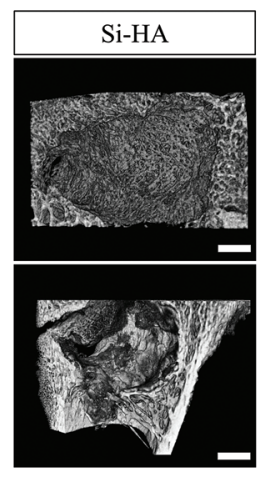

B

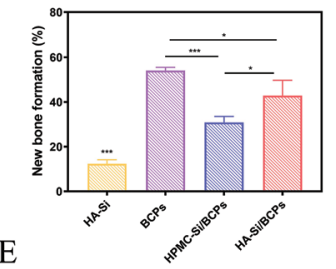

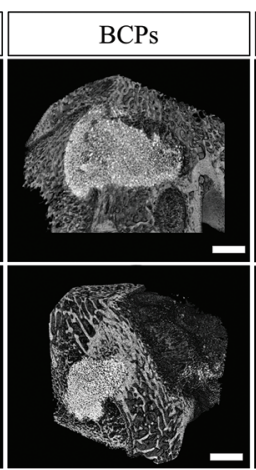

$\mathrm{C}$

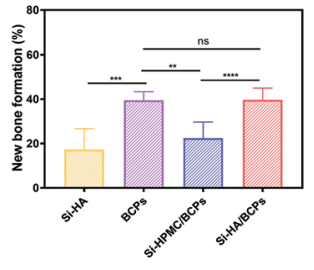

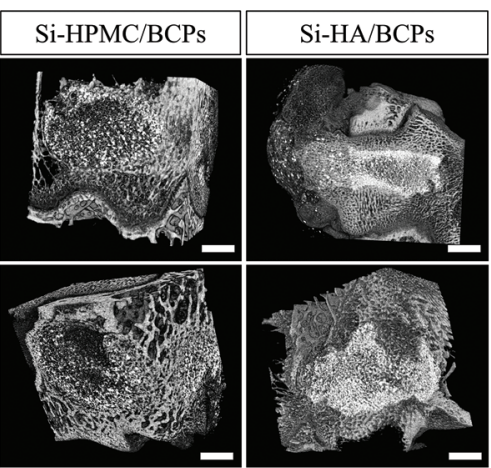

$\mathrm{D}$

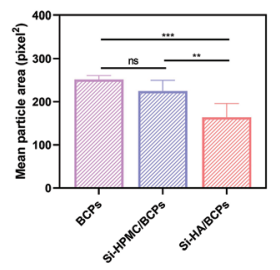

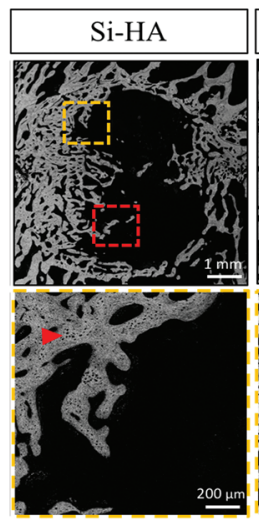
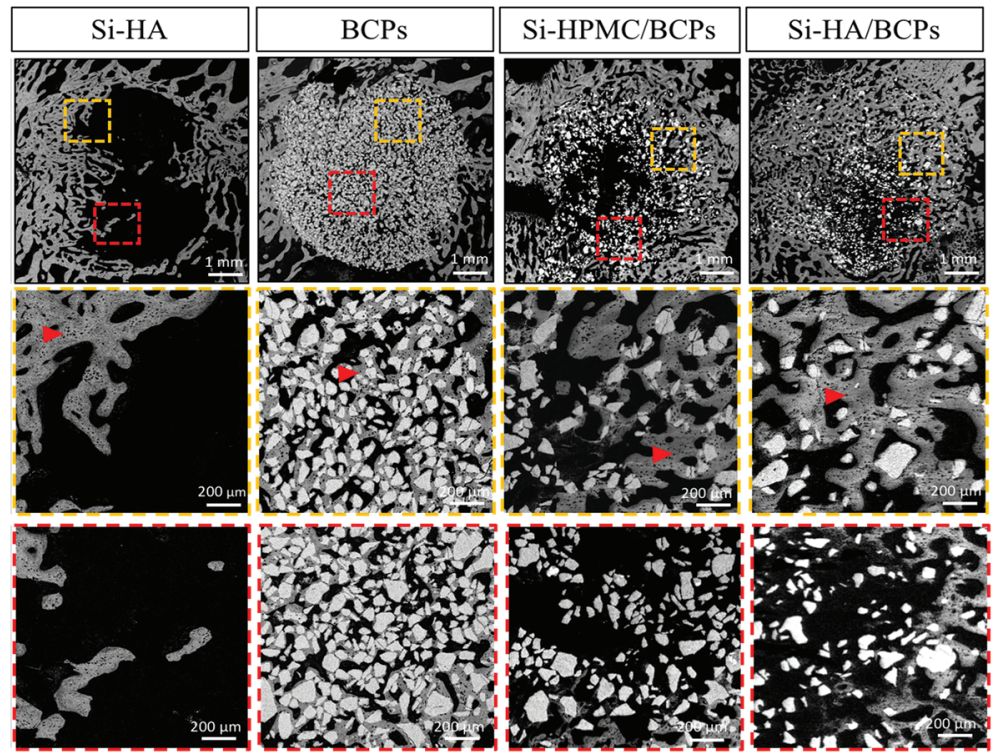

Fig. 3 Evaluation of bone regeneration by $\mu \mathrm{CT}$ and SEM after 4 weeks of implantation in $6 \mathrm{~mm}$ diameter critical size bone defects. (A) Representative 3D reconstructions of the defects. White: BCP granules, gray: host bone and newly formed bone, dark: non-mineralized tissues, (B) quantitative analysis of bone formation obtained by $\mu \mathrm{CT}$ by quantifying the volume occupied by bone tissue divided by the total volume, (C) quantitative analysis of bone formation obtained by SEM by quantifying the are occupied by bone tissue divided by the total area, (D) mean particle area of BCP granules in pixel $^{2}$ determined using the ImageJ software, (E) SEM microradiographs of the polished sections after 4 weeks of implantation in $6 \mathrm{~mm}$ diameter critical size bone defects. Dotted orange and red squares respectively represent a region of interest showing good or limited bone formation. Red arrowheads: osteocyte lacunae. Data are presented as mean \pm SD. Statistical significance was determined by one-way Anova (ns: not significant, ${ }^{*} p<0.05,{ }^{* *} p<0.01,{ }^{* * *} p<0.001,{ }^{* * * *} p<0.0001$ ).

were observed. Strikingly, Si-HA gels alone were poorly degraded after 4 weeks, limiting neo-tissue formation. Similarly, Si-HPMC/BCP samples were still largely observed after 4 weeks (light blue/pink). Although the outer area of the defects showed new bone formation around the granules, the central area was mostly intact, and no cellular infiltration was observed. Conversely, Si-HA/BCP gels were mainly resorbed after 4 weeks, leaving large areas available for cellular infiltration and neovascularization, along with large areas of newly formed bone. Similarly, defects filled with BCP granules alone were fully colonized by cells and were almost fully restored. Only the most central part of the defects was not yet regener- 
A
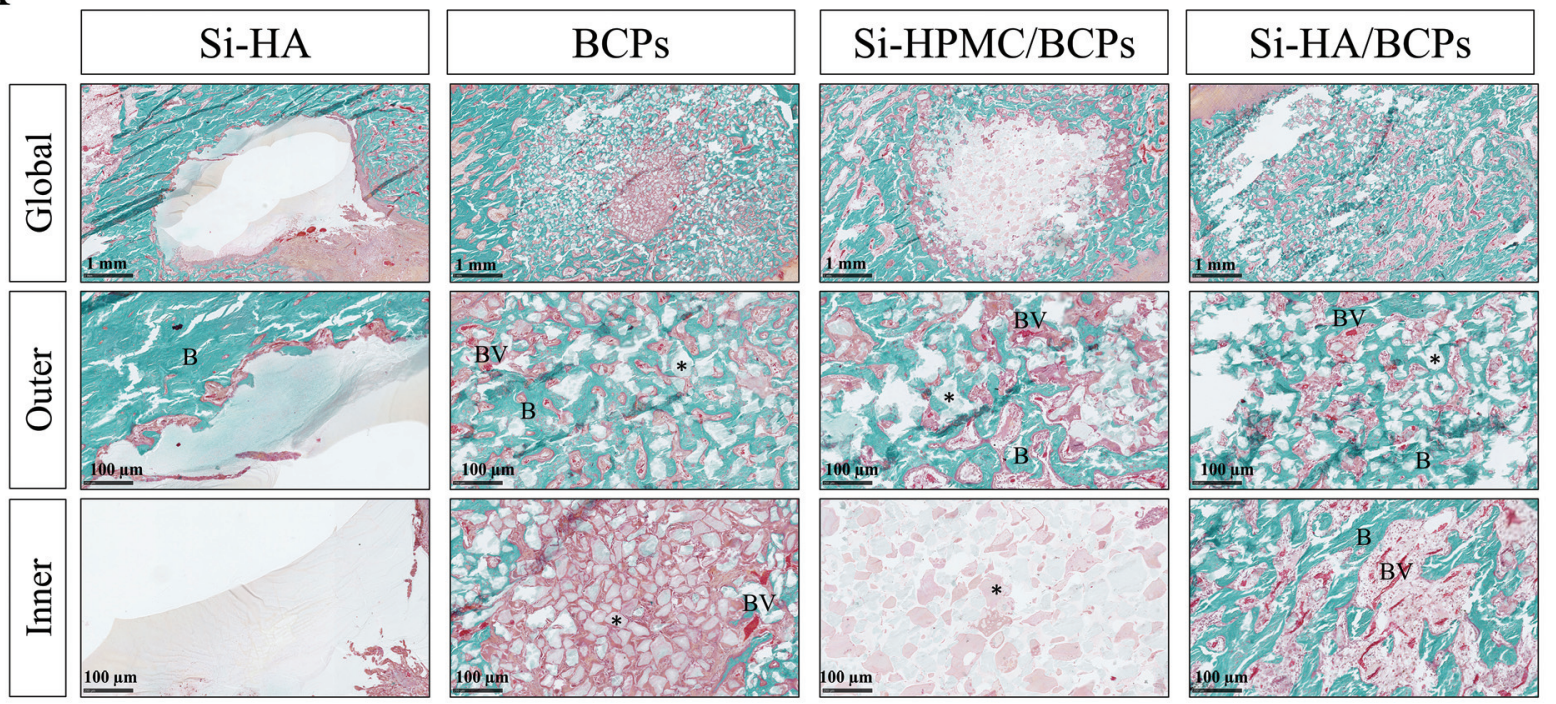

$\mathrm{B}$
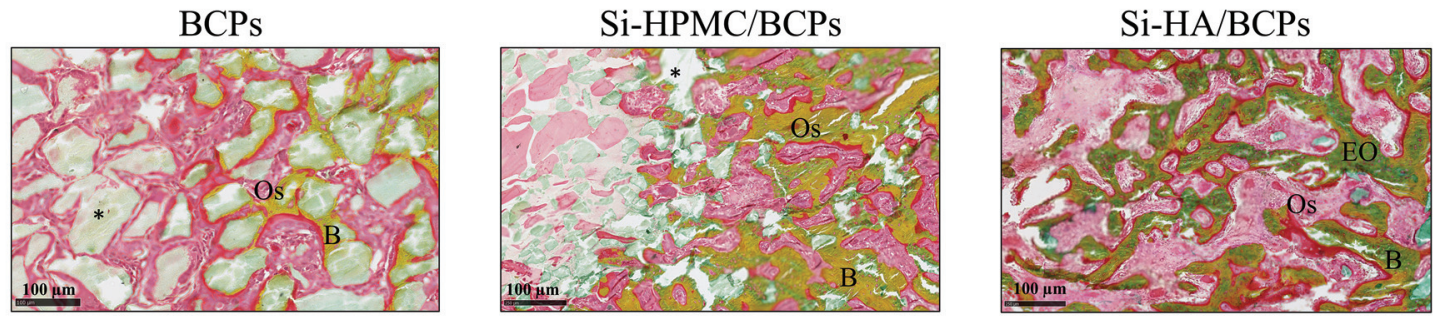

$\mathrm{C}$

$\mathrm{D}$
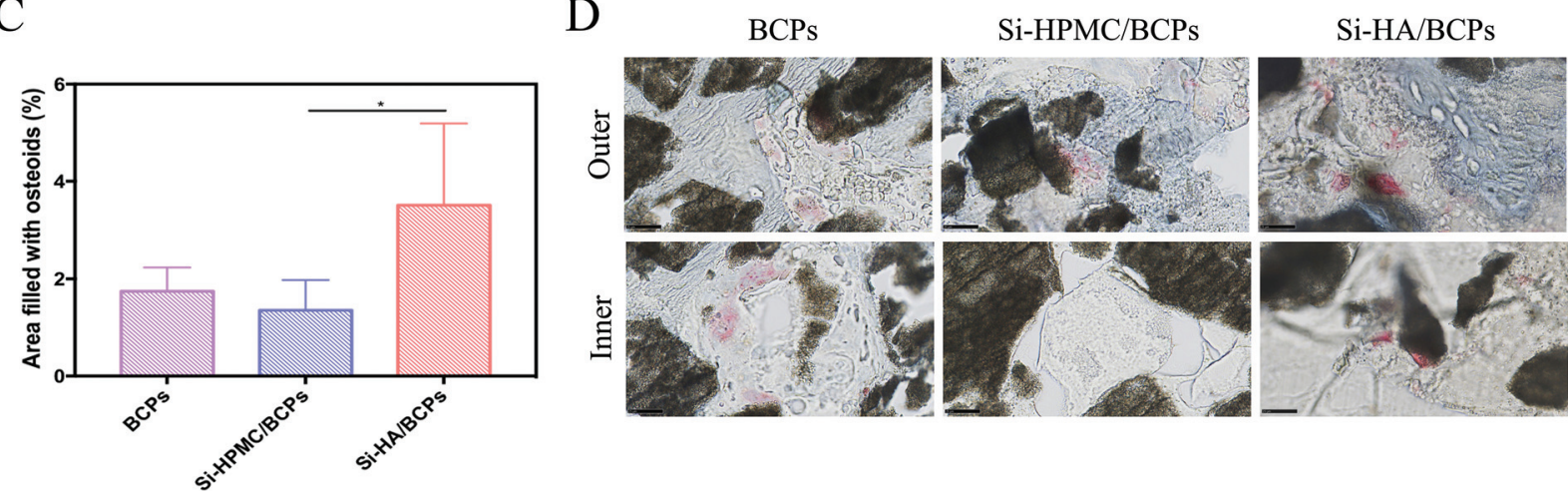

Fig. 4 Evaluation of bone regeneration by histology after 4 weeks implantation in critical-size rabbit defects. (A) Histological evaluation of defects area by Goldner's staining at magnification of $\times 1.5$ (global) and $\times 10$ (inner and outer regions of the defect). Abbreviations: B: bone, BV: blood vessels, *: BCP granules/hydrogel, (B) representative images of bone formation in BCP-containing samples by Masson's pentachrome staining. Abbreviations: Os: osteoid, EO: endochondral ossification, B: bone, *: BCP granules/hydrogel, (C) quantification of the area occupied by osteoid barriers (red) within the defect area, determined by a Python program, (D) TRAP staining showing osteoclastic activities in BCP-containing samples in the inner and outer regions of the defect. Data are presented as mean \pm SD. Statistical significance was determined by one-way Anova $\left({ }^{\star} p<0.05\right)$.

ated, underlying an ongoing mineralization process. For all the BCP-containing conditions, a centripetal ossification pattern was noticed, with an outer area showing advanced regeneration, while the inner areas remained mostly immature. The distribution of BCP granules inside the implants was analyzed in three $2 \mathrm{~mm}$-thick concentric rings (Fig. A5†). A homogeneously distributed population of BCP granules throughout the implant was observed in Si-HA/BCP gels and in the control with BCP granules only. Conversely, more BCP granules were observed in the central part of the defect than at the edge in Si-HPMC/BCP samples, in line with a limited degradation.

To quantify the ongoing tissue mineralization, the total area occupied by osteoid barriers was determined using Masson's trichrome staining and a Python program (Fig. 4B \& A6 + ). A significantly greater area covered by osteoid was noticed in Si-HA/BCP conditions $(3.5 \pm 1.7 \%)$ compared to those filled with Si-HPMC/BCP composites $(1.4 \pm 0.6 \%)$ or BCP 
granules alone $(1.7 \pm 0.5 \%)$ (Fig. $4 \mathrm{C})$. These results indicate a higher bone formation activity in Si-HA/BCP samples. TRAP staining was finally performed to evaluate bone remodeling activity. A bone remodeling activity mediated by the osteoclasts was observed in the outer areas. In addition, osteoclasts could be observed in contact with BCP granules, highlighting their role in BCP resorption (Fig. 4D). An osteoclastic activity in the central region of BCP granules alone and Si-HA/BCP composites could be detected, but not in Si-HPMC/BCP samples, correlating with the reduced degradation of Si-HPMC/BCP samples.

\section{Discussion}

In situ forming bone substitutes are attractive to heal traumatic fractures, fill small cavities after tumor resection, or enable alveolar bone augmentation. ${ }^{29}$ Yet, these biomaterials remain largely unexplored due to the difficult combination of in situ gelation, mechanical stability and osteoconductive properties. $^{30}$ Previously developed Si-HPMC/BCP substitutes showed good injectability, but limited bone regeneration, supposedly due to a slow degradation rate. ${ }^{23}$ In this study, we hypothesized that using a biodegradable HA polymer would overcome this major hindrance and enable bone regeneration in vivo. The present study evaluated and compared the efficacy of two Si-HPMC and Si-HA hydrogels combined with BCP granules to form biphasic injectable composites for bone regeneration. To the best of our knowledge, this is the first study reporting the comparison between two granules-loaded hydrogels for bone filling applications.

To evaluate this hypothesis, Si-HA and Si-HPMC hydrogels were designed to have similar physicochemical properties and crosslinking mechanisms. Both hydrogels showed similar mechanical and rheological properties, suggesting comparable crosslink densities. ${ }^{31}$ Furthermore, both solutions were easily injected, and gelled within $5 \mathrm{~min}$ at $37^{\circ} \mathrm{C}$, which is an optimal gelation time for bone filling applications. ${ }^{9,32}$ As hypothesized, both hydrogels showed different biodegradability in vitro and in vivo after $21 \mathrm{~d}$. In vitro, Si-HA gels were rapidly degraded by hyaluronidases, which specifically cleave $\beta, 1-4$ bonds of the polysaccharide. ${ }^{33}$ On the contrary, Si-HPMC gels were not resorbed by the enzyme, which was expected as cellulosic derivatives are only sensitive to cellulases. In vivo, Si-HA was partially degraded and infiltrated by macrophages, while SiHPMC was found to be stable after $21 \mathrm{~d}$. HA hydrogels are known to be degraded in vivo by hyaluronidases and reactive oxygen species. ${ }^{34}$ Conversely, Si-HPMC gels can only be very slowly degraded by macrophage-mediated phagocytosis. ${ }^{35}$ This lack of degradation induces prolonged stimulation of the inflammatory response, which ultimately leads to a foreignbody reaction characterized by the formation of multinucleated giant cells. ${ }^{36}$ We further incorporated BCP granules to the gel precursors to develop in situ forming bone substitutes. Struillou et al., previously reported that granules $>200 \mu \mathrm{m}$ were hardly injectable. ${ }^{37}$ In addition, smaller particles $(<10 \mu \mathrm{m})$ induce a stronger inflammatory response and a better bone regeneration, ${ }^{38}$ motivating the use of $40-80 \mu \mathrm{m}$ BCP granules. Adding BCP granules did not detrimentally influence the handling and injectability properties, with injection forces lower than the maximal manual injection force generally reported (30-50 N). ${ }^{39} \mathrm{Si}-\mathrm{HPMC} / \mathrm{BCP}$ hydrogels remained insensitive to the hyaluronidase treatment, whereas Si-HA/BCP gels were more rapidly degraded than their BCP-free counterpart. As a lower fraction of the Si-HA precursor solution was used to form the composite, it can be hypothesized that a weaker crosslinked Si-HA scaffold was formed, which is more susceptible to enzymatic degradation. As previously observed, ${ }^{40}$ adding BCP granules mechanically reinforced the hydrogels, indicating that frictions between granules have a greater impact on the stiffness than the hydrogel crosslinked network. In agreement with Trojani et al. and others, ${ }^{59}$ both hydrogels and BCP granules did not alter cell metabolism, indicating good cytocompatibility.

We finally evaluated and compared the ability of Si-HPMC/ BCP and Si-HA/BCP composites to induce bone regeneration in critical size defects. Defects were performed at the distal femoral ends of rabbits to study bone formation without requiring additional reinforcement. ${ }^{41}$ As observed in the study, both the cohesivity and the injectability of the composites were improved by the incorporation of the hydrogel carrier. The extemporaneous preparation of the composite from preloaded syringes was found to conveniently adapt to any clinical situations. Furthermore, the in situ crosslinking mechanism of the gel solves common issues related to granules leakage outside the defect and help maintaining the osteoconductive BCP granules into the defect area. Their cohesivity and malleability can also be used to reach difficult areas where bone regeneration is required. Besides, these injectable bone substitutes could advantageously be used in minimally invasive procedures such as vertebroplasty and kyphoplasty, ${ }^{29}$ or used to encapsulate cells or drugs to further improve bone regeneration. Filling the defects with the Si-HA hydrogel alone did not induce bone regeneration, and histological evaluations revealed limited inflammation and degradation by the host body. Interestingly, Si-HA hydrogel degradation was seemingly slower in the bone defect than in the subcutaneous model. This discrepancy might be explained by different inflammatory responses originating from the use of two different species and implantation sites. ${ }^{42,43}$ Such "blank" hydrogels are rarely reported in the literature, but this study clearly established that bulk hydrogel degradation and bone regeneration may only occur if cells are prone to infiltrate and colonize the material. ${ }^{30}$ In our study, this was achieved by incorporating osteoconductive BCP granules, ${ }^{44}$ but others have used growth factors ${ }^{45}$ or drugs. ${ }^{46}$ As previously reported, ${ }^{47}$ bone formed in contact with the granules, with a centripetal ingrowth from the edge to the central part of the defect. Bone regeneration was quantified by micro-CT (3D) and SEM (2D) and revealed similar trends, with BCP granules alone and Si-HA/BCP composites inducing strong bone regeneration, while Si-HPMC/ BCP gels systematically lead to limited bone healing. This sub- 
optimal regeneration could be explained by the lack of degradability of the Si-HPMC phase, with large areas of non-degraded biomaterials still observed after 4 weeks. Supporting this hypothesis, a higher density of BCP granules was observed in the central part of defects filled with Si-HPMC/BCP hydrogels, whereas the BCP granules were more homogeneously distributed in the BCP and Si-HA/BCP conditions. Although the addition of BCP granules may have stimulated phagocytosis of the HPMC polymer by macrophages, Si-HPMC gels still largely resisted degradation, drastically restricting cell colonization and development of a pre-vasculature network required for bone regeneration. ${ }^{48}$ These results confirm the limited potential of Si-HPMC/BCP as an injectable bone substitute. On the contrary, the comparable level of bone regeneration obtained between Si-HA/BCP gels and BCP granules alone was more remarkable. BCP granules, but not Si-HA/BCP composites, are mixed with blood during implantation, supplementing the biomaterial with growth factors and cytokines/chemokines and facilitating bone healing. ${ }^{49}$ Moreover, Si-HA gels must first be degraded before cell colonization and tissue remodeling can occur, probably initially slowing down the bone forming process. A potential explanation of the improved degradability and bone regeneration capacity of Si-HA/BCP gels may be attributed to an increased "porosity" and inflammatory response towards the biomaterial. As previously reported, BCP granules stimulate the innate immune system by triggering the release of pro-inflammatory cytokines by polymorphonuclear cells. ${ }^{50}$ Together with a lower Si-HA content, the inflammatory environment created by BCP granules probably favored the degradation of the Si-HA/BCP hydrogels. Once degraded, the space between BCP granules was higher than in defects filled with BCP granules alone, creating a "porosity" that may facilitate cellular infiltration and neo-vascularization. Furthermore, small HA fragments originating from degradation products were shown to interact with macrophages through the CD44 receptor of $\mathrm{HA}$, inducing the secretion of pro-inflammatory cytokines, ${ }^{51}$ but also stimulating angiogenesis and tissue remodeling. ${ }^{52}$ Hypothetically, the pro-inflammatory properties of BCP granules, the increased "porosity" following Si-HA resorption, and the inflammatory stimuli originating from HA degradation synergistically stimulated the activation of the innate immune system, which in turn prompted bone remodeling and BCP resorption, as observed in this study and by others. ${ }^{53}$ Moreover, although the positive role of HA in promoting bone regeneration remains controversial, ${ }^{54-56}$ it is well established that plays a biological role in bone tissue formation, ${ }^{57}$ and notably in stimulating osteoblasts activity in vitro. ${ }^{58}$ In our study, significantly more osteoid barriers were observed within Si-HA/BCP composites, suggesting that HA may also stimulate osteoblasts activity in vivo. Consequently, both the biodegradability and the biological properties of the injectable bone scaffold play a central role in guiding tissue regeneration. While both Si-HPMC and Si-HA hydrogels improved the cohesivity and injectability of the bone filling material, only the Si-HA hydrogel showed the ability to regenerate bone defects. Injectable Si-HA/BCP composites are very promising and could be considered as a viable approach to treat small bone defects.

\section{Conclusion}

In this study, we successfully developed and compared in situ forming Si-HA/BCP and Si-HPMC/BCP scaffolds. Both composites were shown to be biocompatible, easily injectable, able to set in clinically relevant time $(<5 \mathrm{~min})$, and with similar mechanical properties $(E \sim 60 \mathrm{kPa})$. After implantation into critical size bone defects, we demonstrated that Si-HPMC/BCP gels led to suboptimal bone formation due to a lack of degradability. On the contrary, Si-HA/BCP composites favored bone regeneration by accelerating $\mathrm{BCP}$ granules turnover and favoring osteoblasts activity. This study highlights the central role played by the degradation rate of hydrogels in controlling bone formation and paves the way for the development of in situ forming and cohesive hybrid Si-HA/BCP scaffolds for bone applications.

\section{Author contributions}

Conceptualization, P. W., K.F., O.G.; methodology, K. F., J. L., J. V., F. A., G. R., O. G., H. G. and P. W.; formal analysis, K. F., F. A., J. V. and P. W., investigation, K. F., A. S., O. G., J. V., J. L. and F. A.; data curation, K. F.; writing - original draft preparation, K. F.; writing - review and editing, K. F., G. R., O. G., H. G., and P. W., project administration, K. F.; supervision, G. R., H. G. and P. W. All authors have read and agreed to the published version of the manuscript.

\section{Conflicts of interest}

A. B. is a member of the private company HTL S.A.S. K. F. is a former member of the HTL company.

\section{Acknowledgements}

We acknowledge the Association Nationale de la Recherche et de la Technologie and the HTL company for funding this work (ANRT no. 2015-1080). We acknowledge the ONIRIS Department of Experimental Surgery, MicroPiCell imaging facility, and SC3M Histology facility of the SFR Santé F Bonamy (UMS INSERM 016/CNRS 3556) (Nantes, France) for their technical support.

\section{Notes and references}

1 B. Baroli, J. Pharm. Sci., 2009, 98, 1317-1375.

2 H. Qu, H. Fu, Z. Han and Y. Sun, RSC Adv., 2019, 9, 2625226262.

3 M. Bohner, Mater. Today, 2010, 13, 24-30. 
4 M. Schumacher, L. Reither, J. Thomas, M. Kampschulte, U. Gbureck, A. Lode and M. Gelinsky, Biomater. Sci., 2017, 5, 578-588.

5 N. Eliaz and N. Metoki, Materials, 2017, 10, 334.

6 G. Daculsi, S. Baroth and R. LeGeros, in Advances in Bioceramics and Porous Ceramics II, John Wiley \& Sons, Ltd, 2010, pp. 45-58.

7 J. M. Bouler, P. Pilet, O. Gauthier and E. Verron, Acta Biomater., 2017, 53, 1-12.

8 I. Titorencu, V. V. Jinga, E. Constantinescu, A. V. Gafencu, C. Ciohodaru, I. Manolescu, C. Zaharia and M. Simionescu, Cytotherapy, 2007, 9, 682-696.

9 G. Daculsi, A. P. Uzel, P. Weiss, E. Goyenvalle and E. Aguado, J. Mater. Sci.: Mater. Med., 2010, 21, 855-861.

10 T. Cordonnier, A. Langonné, P. Corre, A. Renaud, L. Sensebé, P. Rosset, P. Layrolle and J. Sohier, J. Tissue Eng. Regener. Med., 2014, 8, 364-376.

11 H. Kang, Y.-R. V. Shih, M. Nakasaki, H. Kabra and S. Varghese, Sci. Adv., 2016, 2, e1600691.

12 M. Durand, D. Chauveaux, M. Moinard, T. Fabre, J. L. Rouvillain, M. Bagot d'Arc and G. Daculsi, Key Eng. Mater., 2007, 361-363, 1335-1338.

13 S.-H. Jeong, Y.-H. Koh, S.-W. Kim, J.-U. Park, H.-E. Kim and J. Song, Biomacromolecules, 2016, 17, 841-851.

14 P. Weiss, O. Gauthier, J. M. Bouler, G. Grimandi and G. Daculsi, Bone, 1999, 25, 67S-70S.

15 S. Larsson and G. Hannink, Injury, 2011, 42, S30-S34.

16 G. Daculsi, M. Durand, T. Fabre, F. Vogt, A.-P. Uzel and J.-L. Rouvillain, Innovation and Research in Biomedical Engineering, 2012, 33, 254-262.

17 M. D'Este and D. Eglin, Acta Biomater., 2013, 9, 5421-5430.

18 A. Sivashanmugam, R. Arun Kumar, M. Vishnu Priya, S. V. Nair and R. Jayakumar, Eur. Polym. J., 2015, 72, 543565.

19 J. S. Kwon, S. W. Kim, D. Y. Kwon, S. H. Park, A. R. Son, J. H. Kim and M. S. Kim, Biomaterials, 2014, 35, 5337-5346.

20 S. J. Buwalda, A. Bethry, S. Hunger, S. Kandoussi, J. Coudane and B. Nottelet, Eur. J. Pharm. Biopharm., 2019, 139, 232-239.

21 K. Flégeau, R. Pace, H. Gautier, G. Rethore, J. Guicheux, C. Le Visage and P. Weiss, Adv. Colloid Interface Sci., 2017, 247, 589-609.

22 X. Bourges, P. Weiss, G. Daculsi and G. Legeay, Adv. Colloid Interface Sci., 2002, 99, 215-228.

23 B. H. Fellah, P. Weiss, O. Gauthier, T. Rouillon, P. Pilet, G. Daculsi and P. Layrolle, J. Orthop. Res., 2006, 24, 628635.

24 K. Flegeau, C. Toquet, G. Rethore, C. d'Arros, L. Messager, B. Halgand, D. Dupont, F. Autrusseau, J. Lesoeur, J. Veziers, P. Bordat, A. Bresin, J. Guicheux, V. Delplace, H. Gautier and P. Weiss, Adv. Healthcare Mater., 2020, 9, e2000981.

25 K. S. Girish and K. Kemparaju, Life Sci., 2007, 80, 19211943.

26 P. Zhai, X. Peng, B. Li, Y. Liu, H. Sun and X. Li, Int. J. Biol. Macromol., 2020, 151, 1224-1239.
27 B. Gualeni, M.-C. de Vernejoul, C. Marty-Morieux, F. De Leonardis, M. Franchi, L. Monti, A. Forlino, P. Houillier, A. Rossi and V. Geoffroy, Bone, 2013, 54, 83-91.

28 X. Guillory, N. Chopin, P. Weiss, S. Colliec-Jouault and J. Bideau, Eur. Cells Mater., 2014, 28, 40.

29 G. Fernandez de Grado, L. Keller, Y. Idoux-Gillet, Q. Wagner, A.-M. Musset, N. Benkirane-Jessel, F. Bornert and D. Offner, J. Tissue Eng., 2018, 9, DOI: 10.1177/ 2041731418776819.

30 X. Bai, M. Gao, S. Syed, J. Zhuang, X. Xu and X.-Q. Zhang, Bioact. Mater., 2018, 3, 401-417.

31 M. M. E. Koenigs, A. Pal, H. Mortazavi, G. M. Pawar, C. Storm and R. P. Sijbesma, Macromolecules, 2014, 47, 2712-2717.

32 R. Tan, X. Niu, S. Gan and Q. Feng, J. Mater. Sci.: Mater. Med., 2009, 20, 1245-1253.

33 S. P. Zhong, D. Campoccia, P. J. Doherty, R. L. Williams, L. Benedetti and D. F. Williams, Biomaterials, 1994, 15, 359-365.

34 J. Duan and D. L. Kasper, Glycobiology, 2011, 21, 401-409.

35 S. Laïb, B. H. Fellah, A. Fatimi, S. Quillard, C. Vinatier, O. Gauthier, P. Janvier, M. Petit, B. Bujoli, S. Bohic and P. Weiss, Biomaterials, 2009, 30, 1568-1577.

36 B. N. Brown, B. M. Sicari and S. F. Badylak, Front. Immunol., 2014, 5, 510-510.

37 X. Struillou, M. Rakic, Z. Badran, L. Macquigneau, C. Colombeix, P. Pilet, C. Verner, O. Gauthier, P. Weiss and A. Soueidan, J. Mater. Sci.: Mater. Med., 2013, 24, 2749-2760.

38 O. Malard, J. M. Bouler, J. Guicheux, D. Heymann, P. Pilet, C. Coquard and G. Daculsi, J. Biomed. Mater. Res., 1999, 46, 103-111.

39 V. Burckbuchler, G. Mekhloufi, A. P. Giteau, J. L. Grossiord, S. Huille and F. Agnely, Eur. J. Pharm. Biopharm., 2010, 76, 351-356.

40 K. S. Sen, D. F. D. Campos, M. Köpf, A. Blaeser and H. Fischer, Adv. Healthcare Mater., 2018, 7, 1800343.

41 O. Gauthier, E. Goyenvalle, J.-M. Bouler, J. Guicheux, P. Pilet, P. Weiss and G. Daculsi, J. Mater. Sci.: Mater. Med., 2001, 12, 385-390.

42 D. T. Luttikhuizen, M. J. van Amerongen, P. C. de Feijter, A. H. Petersen, M. C. Harmsen and M. J. A. van Luyn, Biomaterials, 2006, 27, 5763-5770.

43 J. Zschaler, D. Schlorke and J. Arnhold, Crit. Rev. Immunol., 2014, 34, 433-454.

44 P. Weiss, P. Layrolle, L. P. Clergeau, B. Enckel, P. Pilet, Y. Amouriq, G. Daculsi and B. Giumelli, Biomaterials, 2007, 28, 3295-3305.

45 K. Minier, A. Touré, M. Fusellier, B. Fellah, B. Bouvy, P. Weiss and O. Gauthier, Vet. Comp. Orthop. Traumatol., 2014, 27, 411-421.

46 I. Arrighi, S. Mark, M. Alvisi, B. von Rechenberg, J. A. Hubbell and J. C. Schense, Biomaterials, 2009, 30, 1763-1771.

47 S. Frasca, F. Norol, C. Le Visage, J.-M. Collombet, D. Letourneur, X. Holy and E. Sariali, J. Mater. Sci. Mater. Med., 2017, 28, 35-35.

48 O. Faruq, B. Kim, A. R. Padalhin, G. H. Lee and B.-T. Lee, J. Biomater. Appl., 2017, 32, 433-445. 
49 H. T. Shiu, B. Goss, C. Lutton, R. Crawford and Y. Xiao, Tissue Eng., Part B, 2014, 20, 697-712.

50 F. Velard, J. Braux, J. Amedee and P. Laquerriere, Acta Biomater., 2013, 9, 4956-4963.

51 M. Litwiniuk, A. Krejner, M. S. Speyrer, A. R. Gauto and T. Grzela, Wounds, 2016, 28, 78-88.

52 J. E. Rayahin, J. S. Buhrman, Y. Zhang, T. J. Koh and R. A. Gemeinhart, ACS Biomater. Sci. Eng., 2015, 1, 481-493.

53 A.-L. Gamblin, M. A. Brennan, A. Renaud, H. Yagita, F. Lézot, D. Heymann, V. Trichet and P. Layrolle, Biomaterials, 2014, 35, 9660-9667.

54 Y. S. Pek, M. Kurisawa, S. Gao, J. E. Chung and J. Y. Ying, Biomaterials, 2009, 30, 822-828.
55 H.-S. Yoo, J.-H. Bae, S.-E. Kim, E.-B. Bae, S.-Y. Kim, K.-H. Choi, K.-O. Moon, C.-M. Jeong and J.-B. Huh, Materials, 2017, 10, 17.

56 W. A. O. Segari, D. A. El Khalek Radwan and M. A. Abd El Hamid, Tanta Dent. J., 2014, 11, 122-129.

57 H. Iwata and M. R. Urist, Clin. Orthop. Relat. Res., 1973, 236-245.

58 L. Huang, Y. Y. Cheng, P. L. Koo, K. M. Lee, L. Qin, J. C. Y. Cheng and S. M. Kumta, J. Biomed. Mater. Res., Part A, 2003, 66A, 880-884.

59 C. Trojani, F. Boukhechba, J.-C. Scimeca, F. Vandenbos, J.-F. Michiels, G. Daculsi, P. Boileau, P. Weiss, G. F. Carle and N. Rochet, Biomaterials, 2006, 27, 3256-3264. 